\title{
ANNEX: THE APPLICATION OF THE ECVET ${ }^{1}$
}

\section{The Rationale for ECVET}

The European Credit System for Vocational Education and Training (ECVET) is a European initiative, allowing for the accumulation and transfer of credits gained through the recognition of learning outcomes in vocational education and training (VET) across Europe. ECVET has been developed to facilitate the recognition of achievements in vocational education and training, in formal, informal and non-formal learning. Although ECVET is underpinned by European legislation, participation is voluntary and national protocols are respected. The ECVET is a technical framework for the recognition, the transfer and capitalization of learning outcomes, designed for vocational education and training in Europe with a view to achieving a qualification.

The aim of ECVET is to facilitate the mobility of the workforce in VET across Europe. It has been tested in pilot projects across the European Union with the intention of extending its application gradually to a wider range of VET qualifications, either existing or new - as part of the Education and Training 2020 initiative $^{2}$.

ECVET facilitates the mobility of VET students by enabling the accumulation of credits from different training providers in different countries. Credits are validated by each awarding institution and recognised by the awarding body of the final qualification.

\section{How Can We Allocate ECVET Points to Qualifications Under EQF Levels?}

After selecting the proper EQF level you need to write down the learning outcomes to be achieved across a transnational mobility. It is not that difficult to define Los in terms of competences, skills and abilities. The difficulty is to match them with the other countries' systems. The qualification is not only described in terms of Los connected to an EQF level, but it is also more modular through its articulation in Units. Moreover, from a practical point of view, the description of a qualification according to the specifications required by ECVET has two complementary functions: mobility size and Lifelong Learning.

1 This annex presents useful information for organizations interested in implementing ECVET.

2 More information can be found at http://ec.europa.eu/education/lifelong-learningpolicy/policy-framework_en.htm. 
Most experts detect the critical aspects arising from the excessive emphasis given to a numerical quantification of the units of competence. Greater importance, however, should be given to the methodological process of the skills assessment., The strategy that prevails seems to recognize a qualitative value (e.g. Exemption from having to support a particular test or examination) rather than the numeric value of each unit of competency.

As a matter of fact, compared to the initial content of the Recommendation, there is much more flexibility in the Commission with reference to the priority of credits between the technical specifications of ECVET and a tendency to give a qualitative rather than numerical value to each unit of competence. It is hoped that the issue related to the recognition of the points can be overcome in the near future towards a more qualitative dimension.

\section{How Can We Define the Procedure of Assessment of Learning Outcomes?}

The assessment procedure has to simply transform the Learning Outcomes outlined for the mobility into questions to be submitted to the host company tutor who is in charge of assessing.

The definition of the procedures for the assessment should play the main role in the technical specifications necessary to enable a recognition method and transparency of qualifications.

In order to achieve validation and recognition of a qualification acquired during a mobility experience, it is important that the competent authority certifies the qualifications according to the agreed methods of assessment. The methodologies must be included in the MoU signed between the companies, while the vocational centre and the competent authority must sign and validate them.

\section{What Are the Roles of ECVET Competent Institutions?}

Without the proper participation of the competent authorities it is simply impossible to put ECVET into practice. Their role is not just to participate to the MoU, but also to validate and certify the Lus and the Los as well as to define and accept the assessment method which has to be shared by the project partners and the competent authority.

The National Agency ECVET and experts can be of support for the implementation of this instrument. 


\section{How Can We Implement a Memorandum of Understanding (MoU) in the Food Sector?}

Items Present in $\mathrm{MoU}$

What is the MoU about and what is its status

It defines the role and responsibility of each project partners stating the basic rules and regulation also for the organisation of the mobility supervised by the competent authorities in each country.

Identification of competent authorities that are sign- Actors involved:

ing the MoU (name of institution, address, etc.)

- National Contact Points

- Competent Organisations that certify the learning

- Training Providers

- Sector organizations

Description of the competent authority signing It depends on the sector the MoU (what is their competence within the qualifications system)

The qualifications concerned by the $\mathrm{MoU}$

Units of learning outcomes

Identification of VET providers who are entitled Learning Providers

to run mobility using ECVET within the framework of the MoU

Information about the nature and/or duration of mobility exchanges

The division of responsibilities with regard to This needs to be agreed mobility between: the HOME ORGANIZATION who does what)

and the HOST ORGANISATION (who does what) Same as above

Commitment to certain quality principles for Same as above different aspects of mobility

Information about who will assess and possibly how Necessary - all partners

Information about how learning outcomes will It is necessary for all partners to agree to this. be validated and recognised
It depends on the sector and the national/local authority. I.e. for the UK, Improve Proficiency Qualifications (IPQs)

I.e. for the UK, units within IPQs 


\section{How Can We Define a Learning Agreement (LA) Among VET Centres in the Food Sector?}

Items for a $L A s$

What is the LA and how to use it

An individualized document which sets out the conditions for a specific mobility period. It specifies, for a particular learner, which learning outcomes and units should be achieved together with the associated ECVET points.

Identification of the home and host institutions To be determined (name of institution, etc.)

Qualification being prepared by the learner

The learning outcomes would reflect those in place in the country of origin so the learning may be recognized

Titles and descriptions of unit(s) of learning Necessary, needs to be shared by all project partners outcomes that are concerned by the specific mobility exchange (what the learner will learn during mobility) and the related ECVET points

Information about the assessment procedure Necessary, all project partners agree to this to ensure for the specific learner (who will assess, when quality assurance and regulation are in place and how)

Basic information about the mobility period: Necessary when will it take place, who is the contact person

Signatures of the three parties (host and home Necessary institution and the learner)

The learning activities the learner will take The learning outcomes will be agreed by the partners, part in during the mobility however the method of delivery should be determined by the learning provider.

Practical aspects concerning the mobility such Necessary for some specific fields of training, less as: language requirements, costs, housing, important, at least at the beginning of the mobility for insurance, etc. other areas.

Overview of who does what (home and host Yes, general overview institution) 
A National Contact Point (NCP) for England has been undertaking some exploratory work in relation to the implementation of ECVET points and initial findings suggest that ECVET and English VET qualifications/QCF system are compatible though further efforts are needed to complete this task. They have also mentioned that a template for converting QCF points into ECVET points (and vice versa) is possible, while the principles which require further assessment include: the understanding of a "year" of learning, the relationship between guided and notional learning hours, sectoral and level-related differences in the learning process. The NCP is currently encouraging stakeholders to consider exploring these findings further and assess whether they can help develop a better way to apply the model.

In Italy, groups of technicians are working to match the two systems, but there are no final results yet. Surely there is a balance between workload and Los. In the initial phase, the EQF was the device used to provide the connection quantity between the two systems, but in Italy this link has not been found thus far. The size of higher education and vocational training highlights large discrepancies, mainly due to time related issues. Almost a decade has passed between the implementation of ECTS and ECVET. The work of the expert groups is primarily designed to realign these two dimensions.

\section{More Information}

http://www.ecvet-projects.eu/ Website that provides ECVET projects information, activities and open seminars to test and favour ECVET implementation in Europe. Special area presents an examples Memorandum. 